\title{
Dyslipidemia in Kuwaiti Adolescents with Type 1 Diabetes
}

\author{
Fatemah Al Otaibi1 ${ }^{*}$, Majida Abdul-Rasool$^{2}$, Reem Yaiesh ${ }^{3}$, Nawal Al Otaibi ${ }^{4}$ \\ ${ }^{1}$ Department of Surgery, Faculty of Medicine, Kuwait University, Kuwait \\ ${ }^{2}$ Department of Pediatrics, Faculty of Medicine, Kuwait University, Kuwait \\ ${ }^{3}$ Department of Medicine, Mubarak AlKabeer Hospital, Ministry of Health, Kuwait \\ ${ }^{4}$ Department of Medicine, Farwanyah Hospital, Ministry of Health, Kuwait \\ Email: ^fatemah.alotaibi@hsc.edu.kw
}

How to cite this paper: Al Otaibi, F., Abdul-Rasool, M., Yaiesh, R. and Al Otaibi, N. (2017) Dyslipidemia in Kuwaiti Adolescents with Type 1 Diabetes. Journal of Diabetes Mellitus, 7, 96-107.

https://doi.org/10.4236/jdm.2017.73008

Received: June 19, 2017

Accepted: July 25, 2017

Published: July 28, 2017

Copyright $\odot 2017$ by authors and Scientific Research Publishing Inc. This work is licensed under the Creative Commons Attribution International License (CC BY 4.0).

http://creativecommons.org/licenses/by/4.0/ (c) (i) Open Access

\begin{abstract}
Objective: Type 1 diabetes mellitus (T1D) and dyslipidemia (DLP) increase the risk of cardiovascular disease (CVD). The objective of this study was to evaluate the progress and perspective of dyslipidemia in young T1D patients. Materials and Methods: The study was cross-sectional and descriptive design. Medical records of T1D patients were followed at an endocrinology service from 2008-2014. The collected data included gender, age, duration of T1D, body mass index (BMI), glycated hemoglobin (HbA1c), total cholesterol (TC), HDL, LDL and triglycerides (TG). Results: 126 T1D patients were recruited: 69 male (54.8\%) and 57 female (45.2\%) with a mean of age 16.4 $( \pm 0.18)$ and $16.5( \pm 0.18)$, respectively. Diabetes duration and baseline HbAlc were $14.82( \pm 2.11)$ and $8.68( \pm 1.21)$, respectively. The HbA1c (average range of $\mathrm{HbAlc} 6.5 \%$ to $10.7 \%$ ) increased significantly while following five years by $2.9 \%(p<0.001)$. The prevalence of overweight and obese teens was increasing from the 1st year to the following five years later. In contrast, the underweight and healthy subjects were decreasing for the same subsequent years. Means of HbAlc were significantly higher among overweight and obese categories throughout following years. All lipid profile revealed significant increase during five years follow-up study. The prevalence of risk TC/HDL ratio $(<4.1)$ gradually raised in the last year follow-up by $52.1 \%$ comparing to the baseline risk ratio $(0.8 \%)$. The study of TC/HDL ratio with BMI categories revealed that average T1D patients had an ideal ratio $(n=97)$ in the 1st year measurement. After five years follow-up study, the frequency of ideal ratio declined among all categories in the same rate. Risk TC/HDL ratio in the last year of the study showed that average group had more risk ratio measurements $(\mathrm{n}=$ 47 ) in contrast to the 1 st year measurement $(n=1)$. The significant positive correlations were reported between $\mathrm{HbAlc}$ and DLP as shown in figure $(\mathrm{r} 2=$ 0.85). $\mathrm{HbA} 1 \mathrm{c}$ and $\mathrm{BMI}$ percentile analyses during long follow-up years were
\end{abstract}


very highly significant differences $(p<0.0001)$ between the categories BMI in each year and from one year to another. Conclusion: Attention must be given to control DLP and other comorbidities among T1D adolescents to decrease diabetes macrovascular and microvascular complications.

\section{Keywords}

Diabetes, Dyslipidemia, DYS, TID

\section{Introduction}

Type 1 diabetes (T1D) is a common childhood disease that is frequently increasing worldwide [1]. Patient with T1D has a lot of chronic complications such as nephropathy, neuropathy, retinopathy, cardiovascular conditions and peripheral vascular diseases [2] [3]. For the long term, these complications have a negative impact on the quality of life of T1D patients [4]. It was revealed that cardiovascular disease occurs in a higher rate and at a younger age among patients with T1D when compared to normal people [5]. The risk of atherosclerosis is $2-4$ times higher in T1D patients compared to people without T1D [6] [7]. The only direct correlation between T1D and cardiovascular diseases is dyslipidemia, which is the elevation of lipids e.g., triglycerides cholesterol and/or fat phospholipids in the blood [8]. The presence of dyslipidemia (DLP) significantly increases cardiovascular risk among patient with T1D [6]. Diabetic dyslipidemia is defined as low levels of high-density lipoprotein cholesterol (HDL-C) and increased low-density lipoprotein cholesterol (LDL-C) and triglycerides (TGs) [9]. A good management of glycemic control is important in treatment of diabetes. Some adolescents may require lipid-lowering medications [8] [10]. Thus, the aim of the study is to determine the prevalence of DLP and its association with clinical and laboratory findings in young patients with T1D from endocrinology referral to manage metabolic control in the future.

\section{Material and Method}

Cross-sectional and retrospective study has been done with around 126 children that were collected from medical records of T1D patients of both genders (chronological age $\geq 12$ years). Patients were followed in the Diabetes Outpatient Clinic at Mubarak AlKaber hospital, ministry of health in Kuwait, from 2010-2016. The collected data included gender, actual age and age at T1D diagnosis, duration of T1D, body mass index $\left(\mathrm{BMI} ; \mathrm{kg} / \mathrm{m}^{2}\right)$; weight $(\mathrm{kg})$, height $(\mathrm{cm})$. In addition, laboratory data, which was collected from the appointment date, including glycemic control (GC); glycated hemoglobin [HbA1c] triglycerides (TG), and total cholesterol (TC, esterase-oxidase) and its fractions high-density lipoprotein [HDL] and low-density lipoprotein [LDL].

Inclusion criteria for children with T1D was the duration of onset diagnosis for more than 5 years and an average range of $\mathrm{HbAlc} 6.5 \%$ to $10.7 \%$ for the past 
six months. The excluded Children from our study included patient who had any coexisting endocrine, genetic or metabolic diseases or taking any medication that affect metabolism (except insulin), psychotropic and weight loss medications.

Descriptive and comparative statistical analyses between the variables were conducted by using Windows version 3.5 (Microsoft Excel and SPSS version 22). The analysis of the qualitative variables used percentage or absolute frequency, and mean and standard error for continuous variables. Comparison between groups or within the same group were made using non-parametric tests. Spearman correlation analysis and multiple regression models were used. A $P$ value $<$ 0.05 was considered statistically significant.

The study was approved by the Ethics in Human and Animal Medical Research committee of HSC.

\section{Results}

Demographic Table 1 showed Age and diabetic duration did not vary significantly within two different genders in type 1 diabetes. However, the average of HbAlc was significant different among female compered to male $(p<0.05)$. The average age of participants that lied between 13 and 18 years old. Since patient's weight with height have been changing during that period (puberty stage), age-specific body mass index (BMI; $\mathrm{kg} / \mathrm{m}^{2}$ ) must be interpreted relative to other children of the same sex and age. Thus, using normal measured BMI for adults is not accurate as BMI percentile estimation.

The Figure 1 shows mean of HbAlc measurements for the following five years on the same patients. Generally, the $\mathrm{HbA1C}$ increased gradually and significantly in both gender, while female patients had highest HbAlc measurements when comparing to male patients. Although baseline year showed significant difference between female and male, no significant difference had been re-

Table 1. Demographic Data (baseline 2010).

\begin{tabular}{cccc}
\hline & Male & Female & Total \\
\hline Frequency $(\%)$ & $69(54.8 \%)$ & $57(45.2 \%)$ & 126 \\
age & $16.4( \pm 0.18)$ & $16.5( \pm 0.18)$ & 126 \\
diabetes duration & $14.7( \pm 0.27)$ & $15( \pm 0.27)$ & 126 \\
HbAlc & $8.5( \pm 0.13)$ & $8.9( \pm 0.18)^{*}$ & 126 \\
BMI & $25.9( \pm 2.2)$ & $25.3( \pm 0.71)$ & 6 \\
BMI Percentile: & & & 99 \\
underweight & & $2(33.3 \%)$ & 15 \\
healthy & $54(54.5 \%)$ & $45(45.9 \%)$ & 6 \\
overweight & $7(46.7 \%)$ & $8(53.3 \%)$ & 126 \\
obese & $4(66.7 \%)$ & $2(33.3 \%)$ & $57(45.6 \%)$ \\
Total & $69(54.8 \%)$ &
\end{tabular}




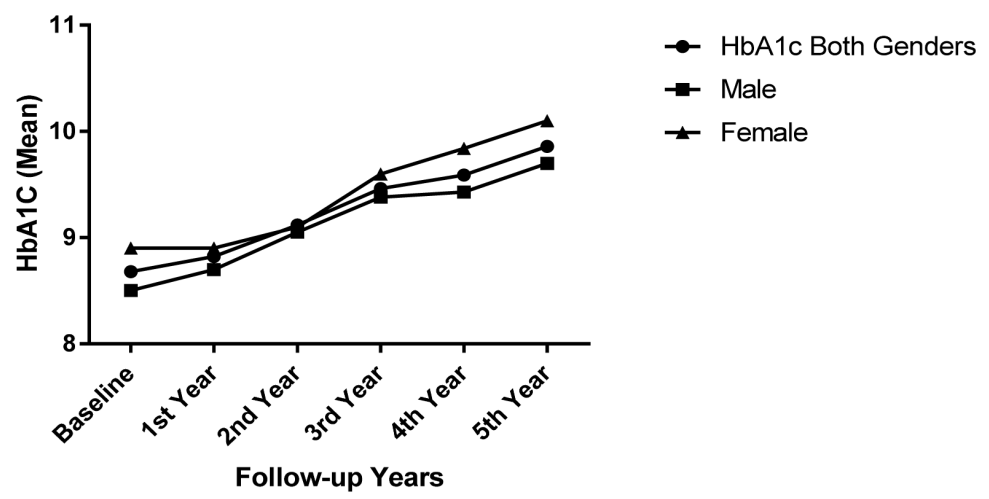

Figure 1. Represented HbAlc baseline measurements (mean and standard errors) with the following five years among male and female participants. The significant difference only occurred in the first year among both genders.

ported in the following study years. The highest percentage change had been occurring occur from $2^{\text {nd }}$ and $3^{\text {rd }}$ following year (4.2\%). While the lowest change percentages were in $1^{\text {st }}$ and $4^{\text {th }}$ year following year.

Table 2 represents the frequency and prevalence for categorical variables (baseline fasting lipid profile) for most participants. None of the participants were treated with lipid-lowering drugs. There were no significant variations between male and female among all parameters of lipid profile. According to the American Academy of Pediatrics, the lipid levels of all parameters have slight different ranges for both children and youth comparing to adultescence. The acceptable LDL-C level is less than $2.85 \mathrm{mmol} / \mathrm{L}$ (100 $\mathrm{mg} / \mathrm{ld}$ ), while acceptable level of HDL-C is more than $1.18 \mathrm{mmol} / \mathrm{L}$ ( $40 \mathrm{mg} / \mathrm{ld}$ ). The healthy levels for both total cholesterol and triacylglyceroll are less than $4.4 \mathrm{mmol} / \mathrm{L}(200 \mathrm{mg} / \mathrm{dl})$ and 1.02 $\mathrm{mmol} / \mathrm{L}(150 \mathrm{mg} / \mathrm{dl})$, respectively. It has clearly shown from the table that most of type 1 diabetes patients (both genders) lied in the acceptable range. DLP was considered when we have at least one of them unsettled.

The lipid profile (TC, HDL-C, LDL-C and TG) have been studied among last five years (2010 to 2016). Chart shows mean concentration and standard deviation (SD) of each of the lipid parameters. All lipid profiles revealed that there were significant variations from baseline measurements to the following five years. Though TC, LDL-C and triglycerides were highly significantly different ( $p$ $<0.0001)$ in comparison to HDL-C $(p<0.001)$ (Figure 2).

The DLP as seen in Figure 3 increased gradually but there were no significant differences among type 1 diabetes patients from baseline to the following five years later.

The significant positive correlations were reported between HbAlc and DLP as shown in Figure $4(\mathrm{r} 2=0.85)$.

\subsection{Ratio TC/HDL}

According to Figure 5 and Figure 6, the prevalence of TC/HDL risk ratio $(<4.1)$ gradually raised after five years follow-up by $52.1 \%$ comparing to the baseline risk ratio $(0.8 \%)$. The study of ideal and risk TC/HDL ratio with different 
Total Lipid Profile

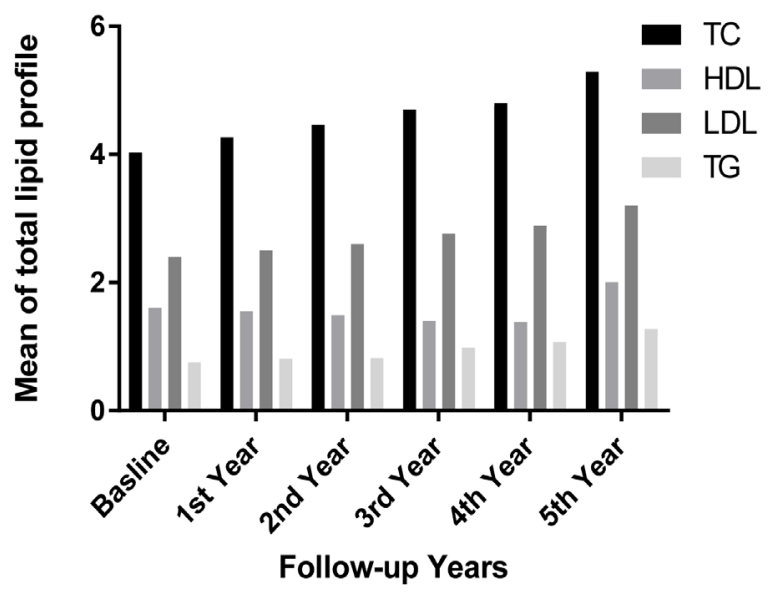

Figure 2. Represented mean of total lipid profile with the following five years among both gender.

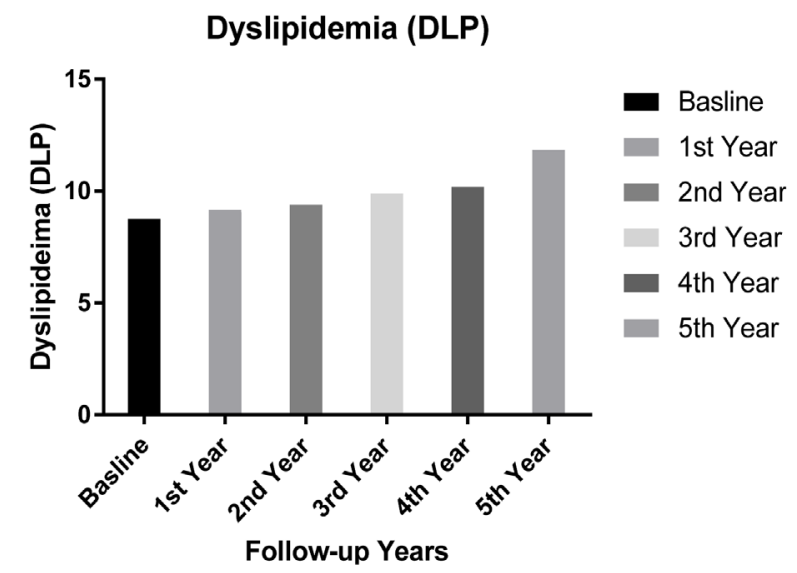

Figure 3. Represented of dyslipidemia, which is elevation of the total cholesterol, the LDL and the triglyceride concentrations, and a decrease in HDL in blood.

BMI categories revealed that average T1D patients had the most ideal ratio ( $\mathrm{n}=$ 97) in contrast to other categories in the baseline year measurement. After five years follow-up study, the frequency of ideal ratio declined among all categories in the same rate. Risk ratio measurements reflected inverse results in all BMI categories especially among average one. During follow-up years, the healthy category of BMI percentile had more risk ratio measurements $(n=47)$ than other categories and comparing to the baseline year measurement $(n=1)$.

According to BMI percentile, Most of T1D patients were healthy comparing to other categories among follow-up five years.

\subsection{HbA1c and BMI Classifications}

The analysis between $\mathrm{HbAlc}$ and BMI percentile during long follow-up years showed very highly significant differences $(p<0.0001)$ between the categories BMI in each year and from one year to another (Figure 7 and Figure 8). 
Table 2. Lipid profile among both gender.

\begin{tabular}{|c|c|c|c|}
\hline Lipid profile (Bassline) & $\begin{array}{c}\text { Male } \\
\text { freq. (\%) }\end{array}$ & $\begin{array}{c}\text { Female } \\
\text { freq. (\%) }\end{array}$ & $\begin{array}{c}\mathrm{X}^{2} \\
(P \text {-value })\end{array}$ \\
\hline \multicolumn{4}{|l|}{ LDL-C $(n=126)$} \\
\hline acceptable & $60(59.4 \%)$ & $41(40.6 \%)$ & \\
\hline borderline & $5(29.4 \%)$ & $12(70.6 \%)$ & 0.07 \\
\hline high & $4(50 \%)$ & $4(50 \%)$ & \\
\hline \multicolumn{4}{|l|}{ HDL-C $(n=125)$} \\
\hline acceptable & $66(55.9 \%)$ & $52(44.1 \%)$ & \\
\hline borderline & 0 & $2(100 \%)$ & 0.23 \\
\hline high risk & $2(40 \%)$ & $3(60 \%)$ & \\
\hline \multicolumn{4}{|l|}{ TC-C $(n=126)$} \\
\hline acceptable & $56(56.6 \%)$ & $43(43.3 \%)$ & \\
\hline borderline & $8(40 \%)$ & $12(60 \%)$ & 0.26 \\
\hline high risk & $5(71.4 \%)$ & $2(28.6 \%)$ & \\
\hline \multicolumn{4}{|l|}{ TG-C $(n=124)$} \\
\hline acceptable & $57(55.3 \%)$ & $46(44.7 \%)$ & \\
\hline borderline & $7(53.8 \%)$ & $6(46.2 \%)$ & 0.92 \\
\hline high risk & $5(62.5 \%)$ & $3(37.5 \%)$ & \\
\hline
\end{tabular}

The LDL level for youth with no other risk factors as follows: Acceptable (Less than $2.85 \mathrm{mmol} / \mathrm{L}$ ), Borderline $(2.85-3.34 \mathrm{mmol} / \mathrm{L})$, High (Greater than $3.35 \mathrm{mmol} / \mathrm{L}$ ). The HDL level for youth with no other risk factors as follows: High risk (Less than $1.04 \mathrm{mmol} / \mathrm{L}$ ), Borderline high $(1.05-1.17 \mathrm{mmol} / \mathrm{L})$, Acceptable (Greater than $1.18 \mathrm{mmol} / \mathrm{L}$ ). The TC level for youth with no other risk factors as follows: Acceptable (Less than $4.4 \mathrm{mmol} / \mathrm{L})$, Borderline high $(4.41-5.16 \mathrm{mmol} / \mathrm{L})$, High (Greater than $5.17 \mathrm{mmol} / \mathrm{L})$. The TG level for youth with no other risk factors as follows: Acceptable (Less than $1.02 \mathrm{mmol} / \mathrm{L})$, Borderline high $(1.03-1.46$ $\mathrm{mmol} / \mathrm{L}$ ), High (Greater than $1.47 \mathrm{mmol} / \mathrm{L})[11]$.

HbA1c vs DLP

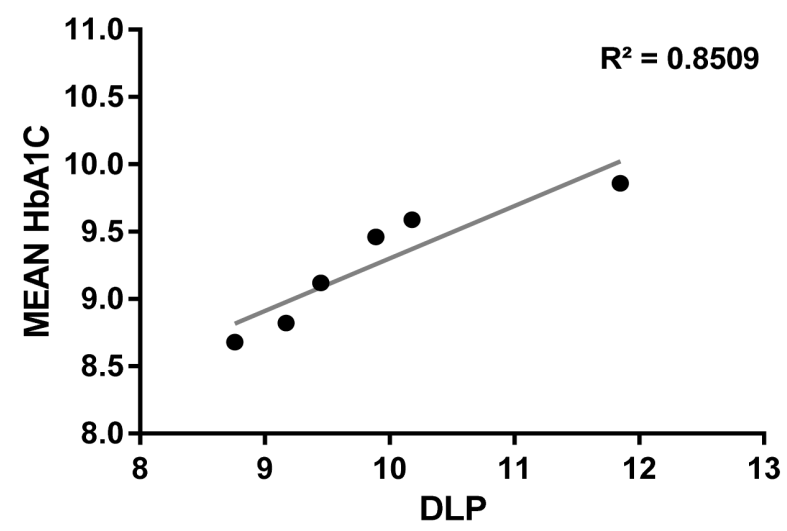

Figure 4. Represented of correlation HbA1c and DLP.

\section{Discussion}

Dyslipidemia in diabetes is a disorder of lipoprotein metabolism that occur when there are high level of TC, TG and LDL with low HDL. The prevalence of dyslipidemia (DLP) has gradually been increasing in general population, including children [12] [13] [14]. Based on our knowledge, most results that in 


\section{TC/HDL ratio}

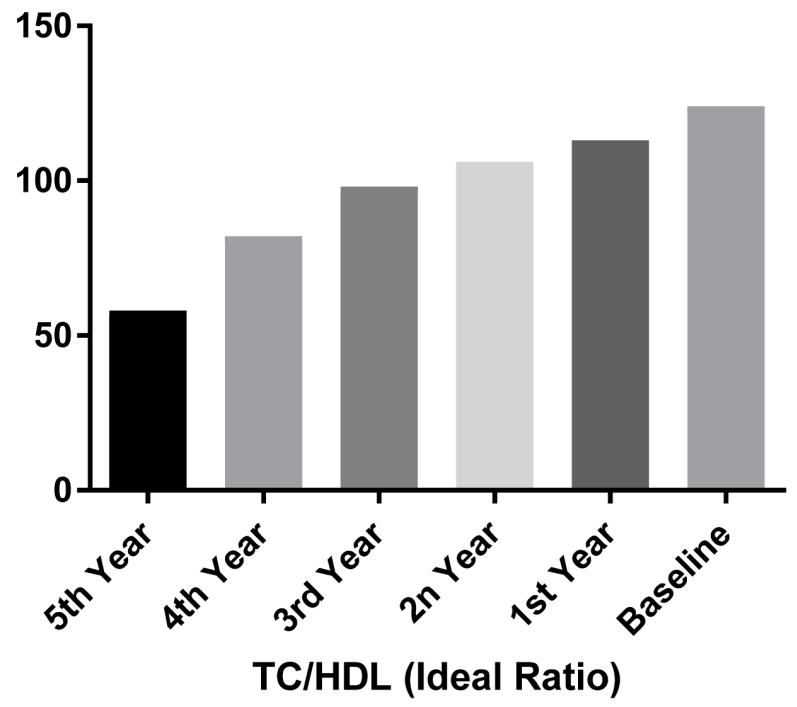

Figure 5. Represented the ideal ratio of TC/HDL (>4.1) among baseline and five years follow-up.

\section{TC/HDL ratio 2}

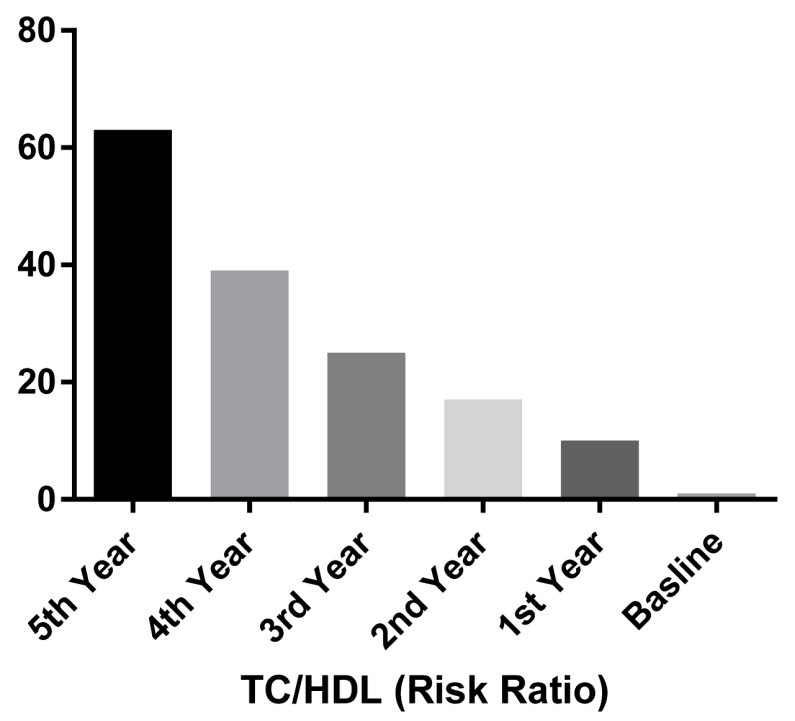

Figure 6. Represented the ideal ratio of TC/HDL $(<4.1)$ among baseline and five years follow-up.

vestigate the relationship between DLP and patients with T1D were done on studies with adult population [15] [16] [17]. Few studies, including ours targeted young T1D patients to document long gradual changes of DLP, HbAlc and BMI. Our study provides support for the importance of clinical and research attention to blood samples and lifestyle of children and adolescents with type 1 diabetes. Strengths include the measurement of lipid profile to monitor changes in adiposity than estimation of BMI percentile, which may show healthy body weight though high complication occur. In addition, our study was not focusing 


\section{BMI vs freq}

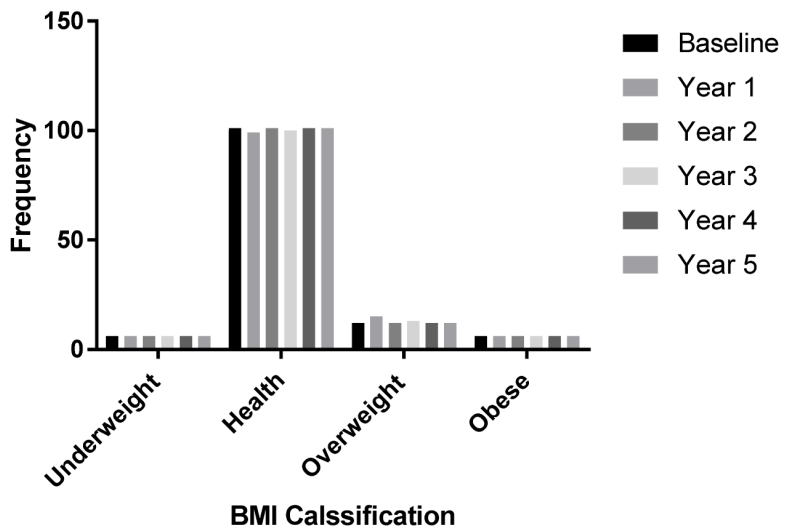

Figure 7. Represented BMI percentile classification among baseline and five years follow-up.

$\mathrm{HbA1c}$ and BMI Classifications

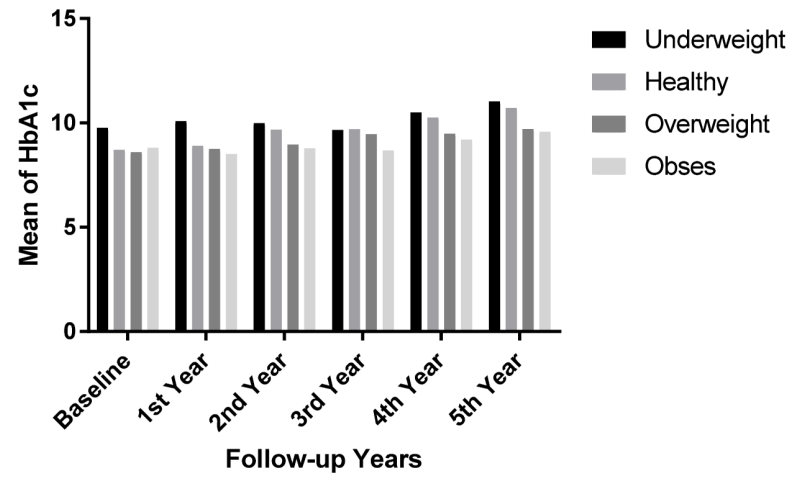

Figure 8. Represented correlation between $\mathrm{HbAlc}$ and BMI classification among baseline and five years follow-up.

on the baseline measurements only, the investigation was done during following up five years from an endocrinology referral, which makes it the first retrospective study in Kuwait among young T1D patient.

The changing in life style, high carbohydrate and low exercise, was found to be the main reason of high DLP and lead to overweight and obesity [18]. Patient with T1D had high DLP level (72.5\%) among young from high level of TC and LDL [12] [14] [19]. In our study, the analysis of LDL during following five years reported the same finding of from high rate of TC and LDL among pubertal patients with TID. Regarding the atherogenic profile, the most commonly reported forms of DLP in patients with T1D include elevated TC, LDL, and TG values [15] [16] [20], which are similar to the findings observed in the present study. In addition to our study we were studying the same lipid parameters for the same patients for five years and reported the same increasing level.

According to demographic data (baseline), the frequency (percentages) of patient's age and diabetes duration showed no significant difference among male and female, while there was a significant difference $(p \leq 0.05)$ in female HbAlc 
comparing to male group.

Since HbA1c, as a marker of glycemic control, is considered to be risk factor for mortality in T1D. Thus, reaching optimal level of $\mathrm{HbA1c}$ remain a significant challenge for T1D patients, including children. As known, people with diabetes always have high level of HbA1c than normal range. Long-term increment increase in HbA1c level may lead to life-threatening complications. So in the current study the differences of HbAlc level for the following five years has been analyzed. It showed noticeable elevation with a very high significant differences $(p<0.001)$ in both genders during five years. According to NICE's national guidelines on type 1 type 2 diabetes in children and young people recommend that children and young people should work hard to make HbAlc near normal range. In addition, Guy and cols [19], and Giuffrida and cols [21] reported correlation between HbAlc and DLP prevalence. These studies match what we found in our research that DLP is correlated positively high with raised level of $\mathrm{HbA1c}$ among following-up five years. That means DLP prevalence may be a good predictor and another red flag to the serious complications and long-term health problems in young T1D patient.

Although DLP lead to cardiovascular diseases in T1D, no long term studies had been done between DLP in T1D and cardiovascular diseases [22]. The only indirect link between development and prognosis of micro and macro vascular complications in adolescents with T1D is measurement of lipid profile [23]. Since coronary heart disease is one of asymptomatic complication associated with obese and overweight hyperinsulinemia patients [24] [25]. Using additional metabolic markers to predict the occurrence and risk of this condition is still a matter of debate. One of these markers is lipid variables, though no universal acceptance of how these markers (lipid profile) should be used and interpreted. It was revealed that determination of lipid ratio (total/HDL cholesterol and LDL/HDL cholesterol) correlated with cardiovascular disease and give an obvious red flag of cardiovascular complications than simple lipid parameter [21] [26] [27]. TC/HDL ratio predicts the risk of CHD from the cumulative markers of cluster metabolic abnormalities found in patients with high TC and low HDL dyslipidemia [28]. It was reported that LDL/HDL ratio underestimate CHD risk in some patients compared to the TC/HDL ratio [29]. This is the reason why current study determine benefit and risk ratio of TC/HDL among young T1D patients for five years. It showed decreasing trend in the ideal ratio in the same opposite increasing rate of risk ratio during study years. So our study predicts the risk of CHD among young T1D patients in spite of the fact that most of these patients were not obese or overweight.

Furthermore, the high prevalence rate of cardiovascular diseases among young T1D patients give more challenge and effort to study and monitor body weight [25] [30]. In the current study, Although duration of T1D is more than 10 years, most of BMI percentile lied in healthy categories from baseline measurements and no changes had been observed during following-up years. Comparing to $\mathrm{HbAlc}$ and lipid profiles, BMI proof that is unpredicted risk factor for 
T1D complications.

Conway and his colleagues had studied the association between adiposity and BMI in the baseline and follow-up years [31]. This study reported that weight gain in adults with T1D is protective against mortality. However, the role of overweight and obesity that had been measured by waist circumference (abdominal fat) increase mortality. As many studies findings that show measured waist circumference eliminate linear relationship between BMI and mortality. In our study poor HbA1c significantly correlated with obsess and overweight patients, Though BM percentiles did not present any noticeable changes, neither at baseline nor throughout follow-up. Which means that BMI percentile can predict risk factor on T1D through measured glycemic control only.

\section{Conclusion}

Glycemic control and lipid profile test are early red flag markers that show dyslipidemia among adolescent with type 1 diabetes. Attention must be given to control DLP and other comorbidities among T1D adolescents to decrease diabetes macrovascular and microvascular complications.

\section{References}

[1] Onkamo, P., et al. (1999) Worldwide Increase in Incidence of Type I Diabetes-The Analysis of the Data on Published Incidence Trends. Diabetologia, 42, 1395-1403. https://doi.org/10.1007/s001250051309

[2] Feitosa, A.C., et al. (2013) Lipoprotein Metabolism in Patients with Type 1 Diabetes under Intensive Insulin Treatment. Lipids in Health and Disease, 12, 15.

https://doi.org/10.1186/1476-511X-12-15

[3] Atkinson, M.A., Eisenbarth, G.S. and Michels, A.W. (2014) Type 1 Diabetes. Lancet, 383, 69-82. https://doi.org/10.1016/S0140-6736(13)60591-7

[4] Simsek, D.G., Aycan, Z., Özen, S., Cetinkaya, S., Kara, C., et al. (2013) Diabetes Care, Glycemic Control, Complications and Concomitant Autoimmune Diseases in Children with Type 1 Diabetes in Turkey: A Multicenter Study. Journal of Clinical Research in Pediatric Endocrinology, 5, 20-26. https://doi.org/10.4274/Jcrpe.893

[5] Laing, S.P., et al. (1999) The British Diabetic Association Cohort Study, II: Cause-Specific Mortality in Patients with Insulin-Treated Diabetes Mellitus. Diabetic Medicine, 16, 466-471. https://doi.org/10.1046/j.1464-5491.1999.00076.x

[6] Schnell, O., et al. (2013) Type 1 Diabetes and Cardiovascular Disease. Cardiovascular Diabetology, 12, 156. https://doi.org/10.1186/1475-2840-12-156

[7] Tomkin, G.H. (2008) Targets for Intervention in Dyslipidemia in Diabetes. Diabetes Care, 31(Suppl 2), S241-S248. https://doi.org/10.2337/dc08-s260

[8] Maahs, D.M., Wadwa, R.P., Bishop, F., Daniels, S.R., Rewers, M., et al. (2008) Dyslipidemia in Youth with Diabetes: To Treat or Not to Treat? The Journal of Pediatrics, 153, 458-465. https://doi.org/10.1016/j.jpeds.2008.05.062

[9] Schwab, K.O., et al. (2010) Characterization of 33488 Children and Adolescents with Type 1 Diabetes Based on the Gender-Specific Increase of Cardiovascular Risk Factors. Pediatric Diabetes, 11, 357-363. https://doi.org/10.1111/j.1399-5448.2010.00665.x

[10] Reh, C.M., et al. (2011) A Longitudinal Assessment of Lipids in Youth with Type 1 
Diabetes. Pediatric Diabetes, 12, 365-371.

https://doi.org/10.1111/j.1399-5448.2010.00733.x

[11] NIH Medline Plus (2012) Cholesterol Levels: What You Need to Know. NIH Medline Plus, Bethesda, Maryland, 6-7.

[12] Lemkes, B.A., et al. (2010) Hyperglycemia: A Prothrombotic Factor? Journal of Thrombosis and Haemostasis, 8, 1663-1669. https://doi.org/10.1111/j.1538-7836.2010.03910.x

[13] Giuliano, I. and Caramelli, B. (2008) Dislipidemias na Infância e na Adolescência. Pediatria, 29, 275-285.

[14] Boni, A., Pugliese, C., Cláudio, C.C., Patin, R.V. and Oliveira, F.L.C. (2010) Vitaminas antioxidantes e Prevenção da Arteriosclerose na Infância. Revista Paulista de Pediatria, 28, 373-380. https://doi.org/10.1590/S0103-05822010000400014

[15] Alves, C., Veiga, S. and Souza, T. (2007) Dislipidemia e Risco de doença Cardiovascular em Crianças e Adolescentes com Diabetes melito Tipo 1. Revista Paulista de Pediatria, 25, 82-89.

[16] Pérez, A., Wägner, A.M., Carreras, G., Giménez, G., Sánchez-Quesada, J.L., Rigla, M., et al. (2000) Prevalence and Phenotypic Distribution of Dyslipidemia in Type 1 Diabetes Mellitus: Effect of Glycemic Control. Archives of Internal Medicine, 160, 2756-2762.

[17] Wadwa, R.P., Kinney, G.L., Maahs, D.M., Snell-Bergeon, J., Hokanson, J.E., Garg, S.K., et al. (2005) Awareness and Treatment of Dyslipidemia in Young Adults with Type 1 Diabetes. Diabetes Care, 28, 51-56. https://doi.org/10.2337/diacare.28.5.1051

[18] Minges, K.E., Whittemore, R. and Grey, M. (2013) Overweight and Obesity in Youth with Type 1 Diabetes. Annual Review of Nursing Research, 31, 47-69. https://doi.org/10.1891/0739-6686.31.47

[19] Guy, J., Ogden, L., Wadwa, R.P., Hamman, R.F., Mayer-Davis, E.J., Liese, A.D., et al. (2009) Lipid and Lipoprotein Profiles in Youth with and without Type $1 \mathrm{Di}$ abetes: the SEARCH for Diabetes in Youth Case-Control Study. Diabetes Care, 32, 416-420. https://doi.org/10.2337/dc08-1775

[20] Arcanjo, C.L., Piccirillo, L.J., Machado, I.V., Jr. de Andrade, C.R.M., Clemente, E.L. and Gomes, M.B. (2005) Avaliação de Dislipidemia e de Índices Antropométricos em Pacientes com Diabetes Mellitus Tipo 1. Endocrinology and Metabolism Clinics of North America, 49, 951-958. https://doi.org/10.1590/s0004-27302005000600015

[21] Giuffrida, F.M., Guedes, A.D., Rocco, E.R., Mory, D.B., Dualib, P., Matos, O.S., et al. (2012) Heterogeneous Behavior of Lipids according to HbA1c Levels Undermines the Plausibility of Metabolic Syndrome in Type 1 Diabetes: Data from a Nationwide Multicenter Survey. Cardiovascular Diabetology, 11, 156. https://doi.org/10.1186/1475-2840-11-156

[22] Hong, Y.M. (2010) Atherosclerotic Cardiovascular Disease Beginning in Childhood. Korean Circulation Journal, 40, 1-9. https://doi.org/10.4070/kcj.2010.40.1.1

[23] Marcovecchio, M.L., et al. (2009) Prevalence of Abnormal Lipid Profiles and the Relationship with the Development of Microalbuminuria in Adolescents with Type 1 Diabetes. Diabetes Care, 32, 658-663. https://doi.org/10.2337/dc08-1641

[24] Soedamah-Muthu, S.S., et al. (2004) Risk Factors for Coronary Heart Disease in Type 1 Diabetic Patients in Europe: the EURODIAB Prospective Complications Study. Diabetes Care, 27, 530-537. https://doi.org/10.2337/diacare.27.2.530

[25] Rodriguez, B.L., et al. (2006) Prevalence of Cardiovascular Disease Risk Factors in U.S. Children and Adolescents with Diabetes: The SEARCH for Diabetes in Youth Study. Diabetes Care, 29, 1891-1896. https://doi.org/10.2337/dc06-0310 
[26] Stampfer, M.J., et al. (1996) A Prospective Study of Triglyceride Level, Low-Density Lipoprotein Particle Diameter, and Risk of Myocardial Infarction. The Journal of the American Medical Association, 276, 882-888. https://doi.org/10.1001/jama.1996.03540110036029

[27] Ridker, P.M., Stampfer, M.J. and Rifai, N. (2001) Novel Risk Factors for Systemic Atherosclerosis: A Comparison of C-Reactive Protein, Fibrinogen, Homocysteine, Lipoprotein(A), and Standard Cholesterol Screening as Predictors of Peripheral Arterial Disease. The Journal of the American Medical Association, 285, 2481-2485. https://doi.org/10.1001/jama.285.19.2481

[28] Kinosian, B., Glick, H. and Garland, G. (1994) Cholesterol and Coronary Heart Disease: Predicting Risks by Levels and Ratios. Annals of Internal Medicine, 121, 641-647. https://doi.org/10.7326/0003-4819-121-9-199411010-00002

[29] Millan, J., et al. (2009) Lipoprotein Ratios: Physiological Significance and Clinical Usefulness in Cardiovascular Prevention. Vascular Health and Risk Management, 5, 757-765.

[30] Liese, A.D., et al. (2011) Association of DASH Diet with Cardiovascular Risk Factors in Youth with Diabetes Mellitus: The SEARCH for Diabetes in Youth Study. Circulation, 123, 1410-1417.

[31] Conway, B., et al. (2009) Adiposity and Mortality in Type 1 Diabetes. International Journal of Obesity, 33, 796-805.

\section{Scientific Research Publishing}

Submit or recommend next manuscript to SCIRP and we will provide best service for you:

Accepting pre-submission inquiries through Email, Facebook, LinkedIn, Twitter, etc. A wide selection of journals (inclusive of 9 subjects, more than 200 journals) Providing 24-hour high-quality service User-friendly online submission system Fair and swift peer-review system Efficient typesetting and proofreading procedure Display of the result of downloads and visits, as well as the number of cited articles Maximum dissemination of your research work

Submit your manuscript at: http://papersubmission.scirp.org/ Or contact jdm@scirp.org 